\title{
ION-1 Technical Manual
}

\author{
J.K. Haibig \\ J.C. Caine
}

\section{DISCLAIMER}

\begin{abstract}
This report was prepared as an account of work sponsored by an agency of the United States Government. Neither the United States Governinent nor any agency thereof, nor any of their bility for the accuracy, completeness, or usefulness, or assumes any legal liability or responsiprocess disclosed, or represents that its usefulness of any information, apparatus, product, or ence herein to any specific commercial product manufacturer, or otherwise does not necessarily constitute or service by trade name, trademark, mendation, or favoring by the United States constitute or imply its endorsement, recomand opinions of authors expressed herein do Government or any agency thereof. The views United States Government or any agency thereof.
\end{abstract}


ABSTRACT

INTRODUCTION

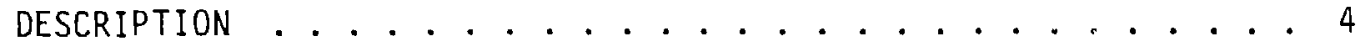

Physical Components............... . . . 5

Front Panel . . . . . . . . . . . . . . 5

Rear Panel................. 5

Circuit Board and Power Supply............ 5

Rear-Panel Connectors . . . . . . . . . . . . . 5

Ion Chamber ................. . 5

Pulse (Neutron) Detector ............ . . . 9

Battery Charger . . . . . . . . . . . . . . 9

Serial Port ................ . . . 9

Auxiliary Port................. . . 10

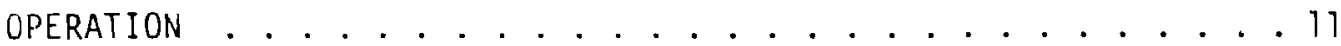

Measurements ....................... . . 11

Ganma ................... . . 11

Neutrons . . . . . . . . . . . . . . . 11

Preamplifier . . . . . . . . . . . . . . . . 12

Power....................... 12

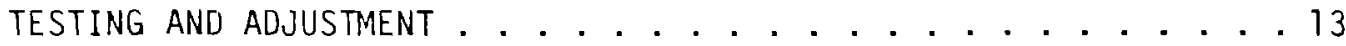

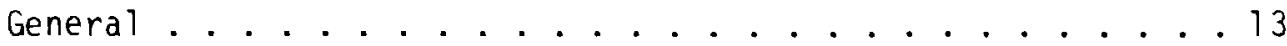

Supply and Reference Voltages............. 13

Battery Voltage ................ . . 13

Power Supply Output Voltages ............ . 13

Main and Display Board Digital Voltages........ 14

Analog Circuitry Voltages ............ . 15

Pulse Channel Adjustments. . . . . . . . . . . . . . . 17

LLD Function . . . . . . . . . . . . . . 17

Neutron Channel Logic Pulse ............. . . 18

Current Channel Zero Adjustment . . . . . . . . . . . . 19

Crystal Frequency ................. 19

Bias Supply Voltage Adjustments..............20

Ion Chamber Bias Range ............. . 20

Fission Chamber Bias Voltage Range . . . . . . . . .20

Preamp Power Voltages ............... . . 20

Voltage Readout ................. . 20

Current Channel ............... . . 20 
CIRCUITRY ...................... . . . . 24

Current Chânnei ................ 24

Analog Multiplexer and Analog-to-Digital Converter .... 25

Pulse Channel .................. . 26

Power Supply . . . . . . . . . . . . . . . . 27

Battery Supply............... . . 27

Digital and Analog Voltages ............. . . 28

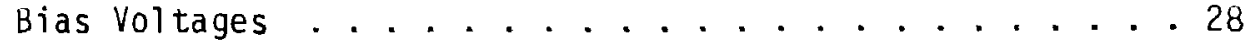

Vol tage Display .................. . . . 28

Digital Control Processor . . . . . . . . . . . . 29

Front Panel .................. . . 29

LCD Module...................... . . 29

Keypad Scan ................... . . 30

Serial Interface . . . . . . . . . . . . . . 30

Real-Time Clock ............... 30

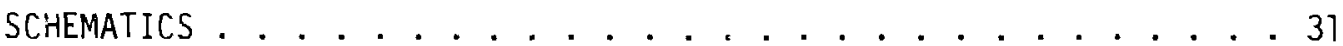


ION-T TECHNICAL MANUAL

by

J. K. Halbig and I. C. Caine

\begin{abstract}
The portable gammia-ray and neutron detector electronics (ION-1) gives a digital readout of the current-mode response produced by gamma rays in an ion chamber and of amplification and scaling of pulses received from a neutron detector. The primary application is the measurement of gamma-ray and neutron activity of irradiated reactor fuels stored at a reactor or at a storage pond away from a reactor.

ION-1 is the first such instrument to use a design that allows communication of procedures, responses, and results between instrument and inspector. It prompts the inspector through procedures, carries out programmed measurement steps, calculates results and error estimates, and performs internal diagnostic checks.
\end{abstract}

This Technical Manual describes adjustment procedures and 1 imited technical information that enable the inspector to troubleshoot at the board level. 


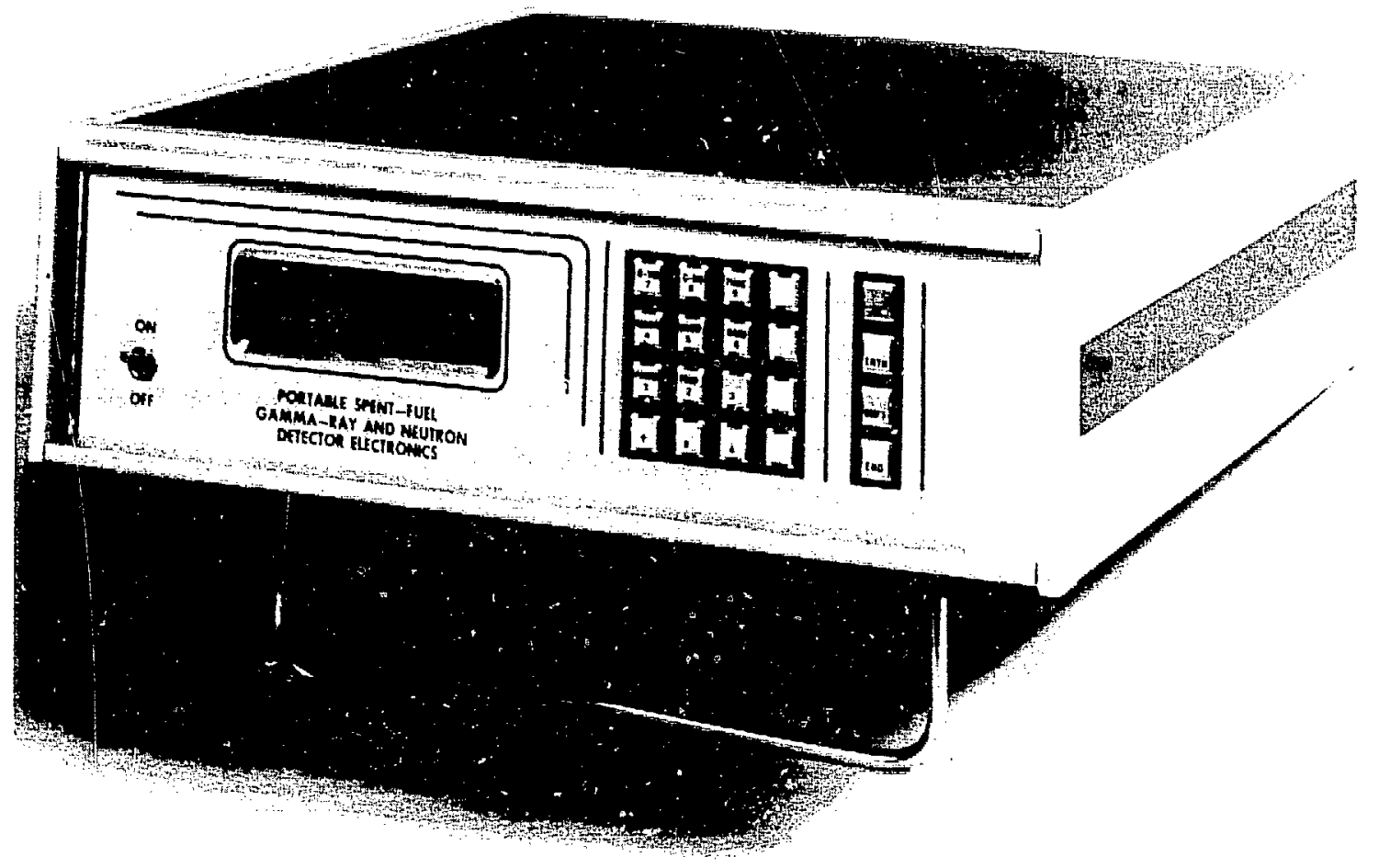


The intelligent, portable, spent-fuel gamma-ray and neutron detector electronics (ION-1) represents a revolutionary step in the design of instruments used by the International Atomic Energy Agency. Such instruments prompt the inspector through measurements, perform internal diagnostics, and make some decisions without inspector interaction. The inspector can concentrate on the measurement's meaning without being distracted by having to remember detailed procedures, check hand calculations, or worry that an instrument is not working properly.

Two manuals accompany ION-1. The User Manual, provided by the manufacturer, describes the operation of the instrument and supplies a minimum of technical information. This Technical Manual is a companinn to the User Manual. It gives the inspector a general understanding of the basic operation of the unit, explains adjustment procedures, and gives nominal values for important parameters. This manual is sufficiently detailed that a knowledgeable person can make adjustments to and perform limited maintenance on the unit. It is not a complete maintenance manual. However, its user can identify maintenance problems at the board level and replace boards to repair a malfunctioning unit.

If it is necessary to set up or repair ION-1, carry out the procedures in the TESTING AND ADJUSTMENT section of this manual. However, an inspector who is not already familiar with $I O N-T$ and its operation should first read the OESCRIPTION and OPERATION sections. 
Fig. 1. Chassis wiring diagram (system interconnections). 
PHYSICAL COMPONENTS

Front Panel

Rear Pane?

Circuit Board and

Power Supply

Figure 1 is an overview wiring diagram. See CIRCUITRY for detailed wiring diagrams and discussion.

On the front panel (Fig. 2) are the following:
(A) power switch
(B) 32-character (ASCII) display
(C) control and entry/command keypads
(D) charger-operating LED (1ight-emitting diode).

On the rear panel (Fig. 3) are the following:
(A) battery charger input
(B) fission chamber high-voltage output
(C) fission chamber signal input
(D) neutron channel amplifier output
(E) fission chamber preamplifier dc power output
(F) auxiliary parallel I/0 connector
(G) RS-232 serial interface connector
(H) ion chamber signal input
(T) retaining screws.

The main circuit board (Fig. 4) is in the top of the box. The power supply board and batteries (Fig. 5) are in the lower compartment. A metal shield mounted inside the rear panel encloses the high-vol tage supplies.

REAR-PANEL CONNECTORS Ion Chamber
The twin-axial connector (Fig. 3,H) supplies both the bias for and signal input from the ion chamber. The connector shell is the terminal for the cable shield. The pin is the signal input, 


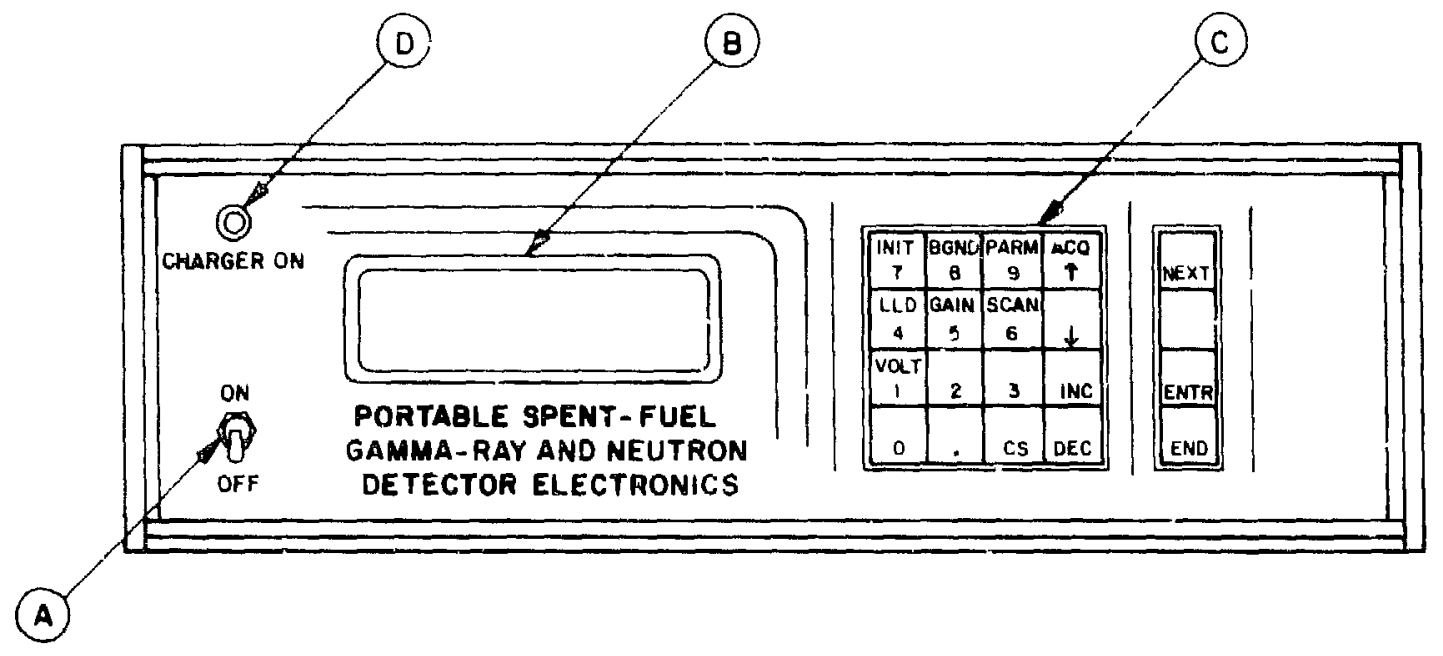

Fig. 2. ION-1 front pane1.

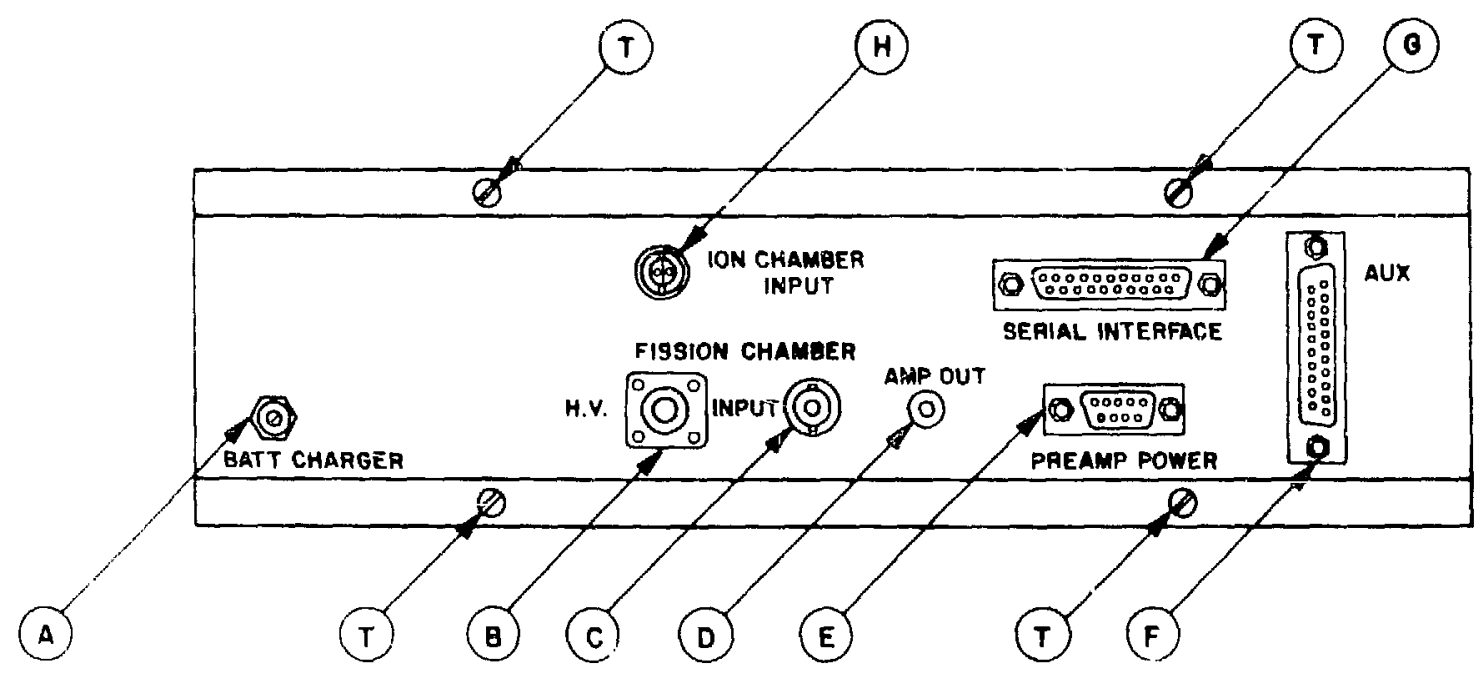

Fig. 3. ION-1 rear pane1. 


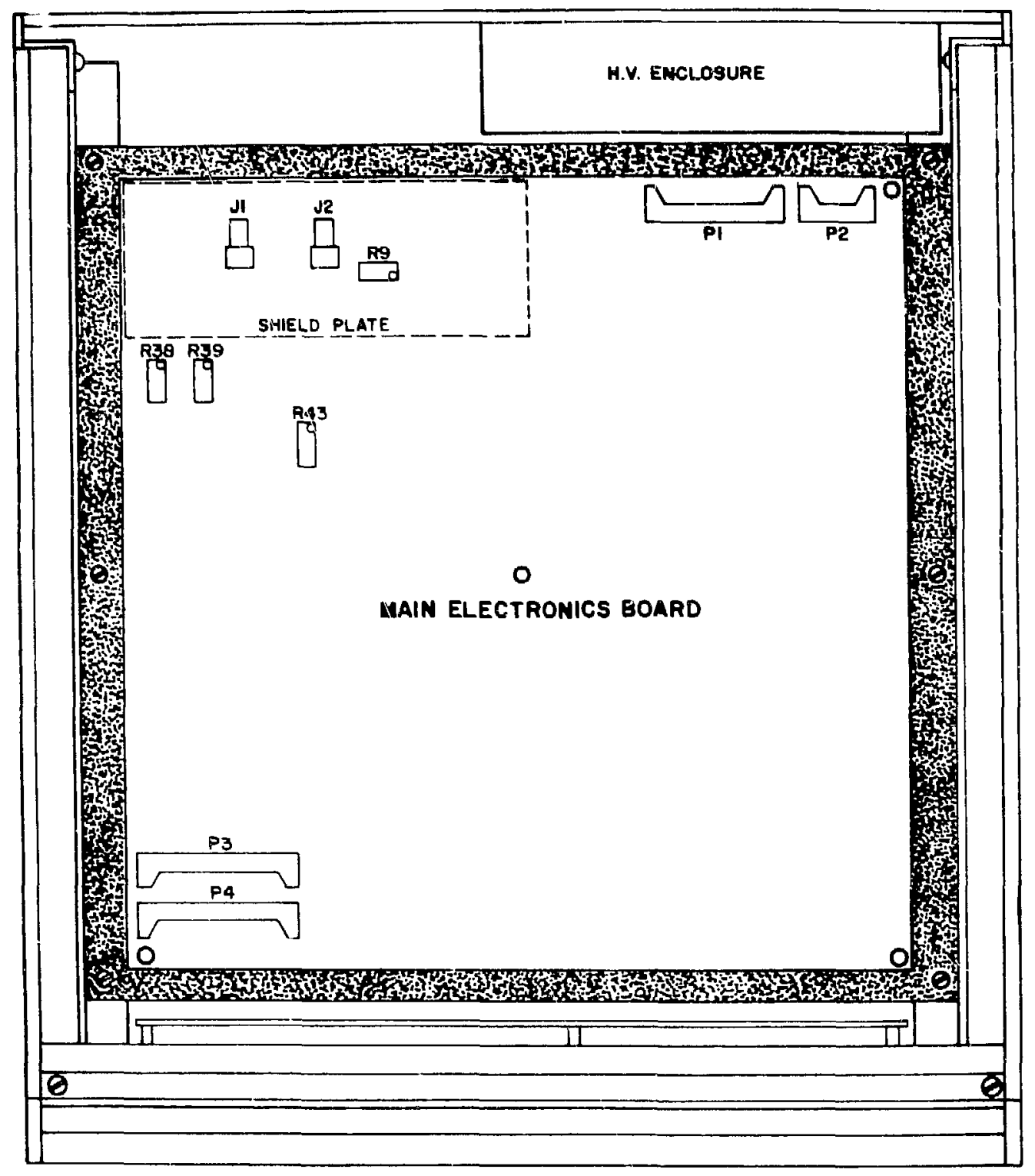

Fig. 4. Main circuit board in upper part of ION-1. 


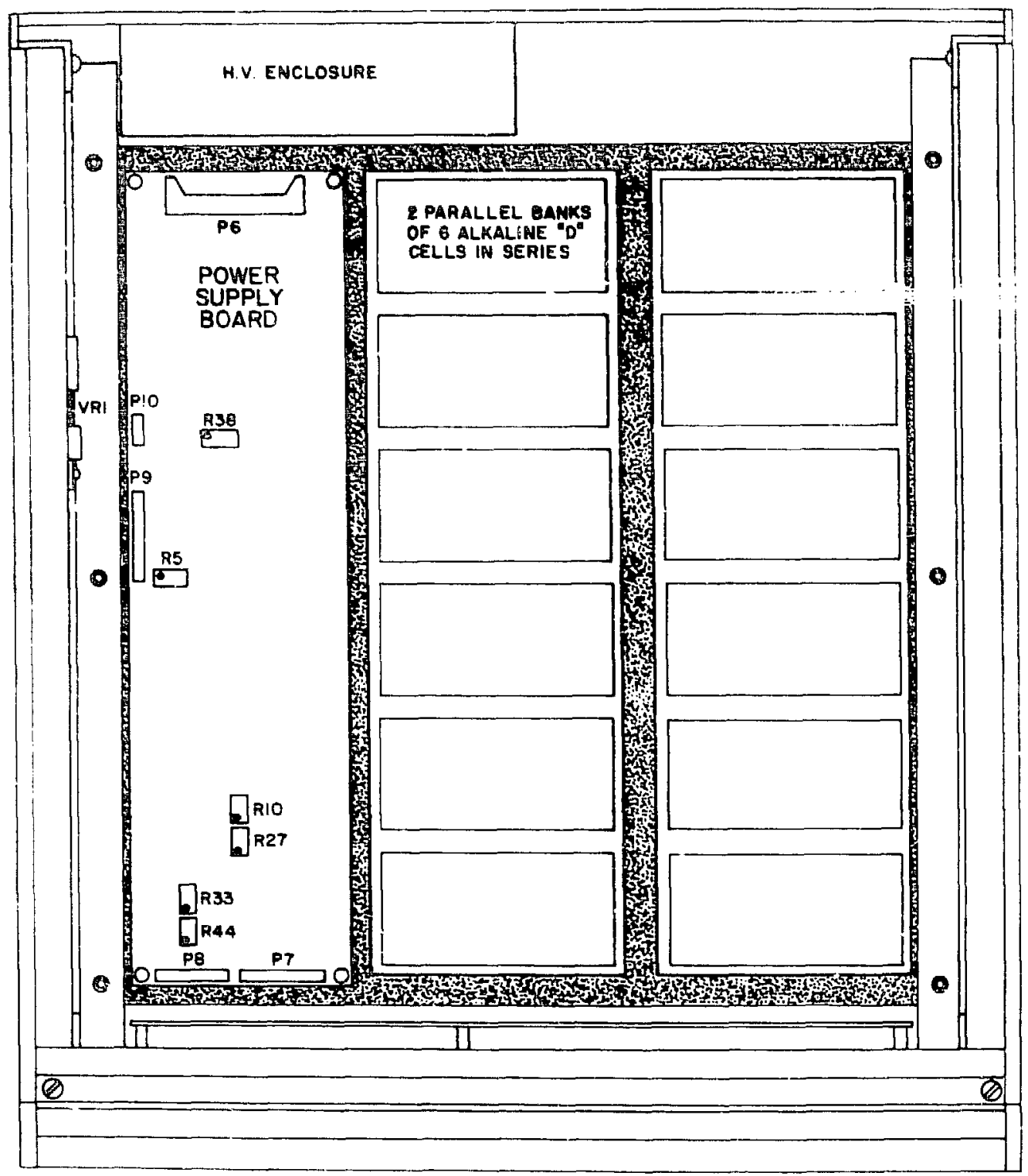

Fig. 5. Power supply board and batteries in lower part of ION-1. 
Ion Chamber

(cont)

Puīse (Neutron)

Detector and the socket is the bias output. (The bias is typically $-100 \mathrm{~V} .1$

The bias is supplied through the SHV connector (Fig. 3,B). The bias is positive and is adjustable from 500 to $1500 \mathrm{~V}$. Preamplifier power is supplied from the 9-pin L-connector (Fig. 3,E). The pin-out of the cornector is as follows:

\begin{tabular}{c} 
Pin \\
\hline 1 \\
2 \\
4 \\
9
\end{tabular}

The signal input (Fig. $3, C$ ) is a standard BNC connector. An amplifier output signal is provided at the Lemo connectur (Fig. 3,D).

Battery Charger The battery charger connector is an input for 22 to $24 \mathrm{Vdc}$ at $0.8 \mathrm{~A}$ from an external source. The charger input to $10 N-1$ should be filtered direct current. The power input supplies power to the main electronics in place of batteries, and it supplies power to charge the batteries. Internal to ION-1 are a constant-current charger circuit for the batteries and a $12-V$ passive regulator that regulates the input power for the main electronics.

Serial Port

The 25-pin, female D-connector (Fig. 3,G) marked SERIAL INTERFACE is used for serial communication. The signal levels are compatible with RS-232 
Serial Port

(cont)

Auxiliary Port specifications, and the following signals are on the pins:

Pin
1
2
3
5
6
7
8
20

Signal

Chassis GND ( $n / c)$

ION-1 receive data

ION-1 transmit data

*

Signal GNU

*

*Jumpered together in ION-T.

The auxiliary port supplies $\varepsilon$ bits of input and 8 bits of output. The 25-pin, female D-connector marked AUX (Fig. 3,F) has the following pin-out.

\begin{tabular}{|c|c|c|c|}
\hline Pin & Function & Pin & Function \\
\hline 1 & IN 0 & 14 & IN 1 \\
\hline 2 & IN 2 & 15 & IN 3 \\
\hline 3 & IN 4 & 16 & IN 5 \\
\hline 4 & IN 6 & 17 & IN 7 \\
\hline 5 & OUT 0 & 18 & OUT 1 \\
\hline 5 & OUT 2 & 19 & OUT 3 \\
\hline 7 & OUT 4 & 20 & OUT 5 \\
\hline 0 & OUT 6 & 21 & OUT 7 \\
\hline
\end{tabular}

This interface can be used with a parallel-type printer interface or for external control or status read-back of external devices. It is not. supported by the software at this time. 
MEASUREMENTS

Gamma

Neutrons
ION-1 measures the current-mode response of a gasfilled ion chamber (gamma signal) and measures neutrons by amplifying and scaling pulses received from a neutron detector, specifically a ${ }^{235} \mathrm{U}$ fission chamber or B-10 chamber.

ION-1 measures gamma dose rate with an ion chamber operating in the current mode. The sensitivity of the actual measurement is dependent on both the current sensitivity of ION-I and the gamma sensitivity of the ion chamber used. The sensitivity of the ION-1 gamma signal channel ranges from 0.0001 to 2557 relative units (one unit nominally corresponds to $2.50 \times 10^{-10} \mathrm{~A}$ ). The conversion of gamma signal value to gamma dose is a function of the specific ion cnamber used.

The pulse-counting channel counts neutrons detected in a fission chamber, al though it can count most types of pulses typically found in nuclear counting applications. (There is a 10to 15- $\mathrm{s}$ fixed deadtime.) The input is differentiated with $0.5-\mu$ s time constant, and the signal is amplified by 50 . The amplifier output is fed to a low-level discriminator (LLD), whose value is set through software from the front pane 1 controls. ION-1 counts pulses that exceed the LLD. The neutron scaler counts 65535 pulses before overflowing, and the inspector can set the neutron counting period from 1 to $65535 \mathrm{~s}$. 
PREAMPLIFIER

POWER
The preamplifier for the neutron electronics should be as near the neutron detector as the radiation field permits. The preamplifier generally used is of the same design as the preamplifier in the high-level neutron coincidence counter now used by the International Atomic Energy Agency.

ION-1 supplies dc power to the neutron detector preamplifier and high-voltage bias to the ion chamber and fissiun chamber.

Six or twelve D-cell batteries power ION-1, which is supplied with rechargeable nickel-cadmium (NiCad) cells and a charging supply. With the cells that are supplied, the operating time per charge is longer than two 8 -h working days, and the cells can be recharged in 12 to $16 \mathrm{~h}$. In the event of cell or charger failure, you may replace the cells with alkaline D-cells.

CAUTION: Do not operate the ION-1 with non-NiCad cells when the charger is plugged in. You can use the unit with the charger and no cells. 
GEMERAL

SUPPLY AND REFERENCE VOLTAGES

Battery Vcitage

Power Supply Output Voltages
If your ION-T is new or fails during operation, follow these testing and adjustment steps.

1. With the power switch OFF, check the battely - 1 tage.

After charging the batteries for more than $12 \mathrm{~h}$, measure the battery voltage input to the power suppiy board between P9-8 and P9-7 (see Dwg No. 101Y-230839-D4).

IF the voltage is $\geq 7.5 \mathrm{~V}$, go to step 2 ,

If the voltage is $<7.5 \mathrm{~V}$, replace the batteries with NiCad D-cells of $4 \mathrm{~A} / \mathrm{h}$ capacity OR charge the batteries overnight and remeasure the voltage.

2. With the power switch OFF, remove the cable connector from P6 on the power supply board. On Dwg No. 10? Y-230839-D4, P6 is show.1 as two parts, $\mathrm{P} 6-1$ and $\mathrm{P} 6-2$.

Turn the power switch ON.

Measure the $\pm 5 \mathrm{Vdc}$ and $\pm 15 \mathrm{Vdc}$ outputs on P6 pins. Table I lists pin numbers and acceptable voltage ranges. 
TABLE I

POWER SUPPLY VOLTAGE AND TEST POINTS

\begin{tabular}{|c|c|c|}
\hline Voltage & $\begin{array}{c}\text { Acceptable } \\
\text { Vol tage Range } \\
\text { (Vdc) } \\
\end{array}$ & $\begin{array}{l}\text { Dwg No. } \\
101 Y-230839-D 4 \\
\text { P-6 Pin No. }\end{array}$ \\
\hline $\begin{array}{l}+5 \\
-5 \\
+15 \\
-15 \\
\text { Common }\end{array}$ & $\begin{array}{r}4.75 \text { to } 5.4 \\
-4.0 \text { to }-6.0 \\
15.0 \text { to } 16.0 \\
-14.0 \text { to }-15.0\end{array}$ & $\begin{array}{r}16 \\
20 \\
12 \\
8 \\
14,15,18, \\
7,10 \text {, or } 11\end{array}$ \\
\hline
\end{tabular}

Power Supply Output Vol tages

(cont)

3. Turn the power switch $\mathrm{ON}$ and look at the frontpanel display.

If the display is present and seems normal, go to step 4.

If the display is missing or is abnormal in contrast, measure the +5 Vdc supply voltage at any of the logic integrated circuits on the main printed circuit board and on the display board. The $-5 \mathrm{Vdc}$ voltage can be measured on Pin 2 of connector P2 of the display board. Use Dwg Nos. 101Y-230858-01 and -02 to identify the components on the main circuit board and 
Main and Display

Board Digital Voltages

(cont)

Dwg No. $101 Y-230858-D 3$ to identify components on the display board.

IF the voltage levels are correct, but the display is still missing or is abncrmal, you must use a logic-state analyzer and standard disital logic troubleshooting techniques to find and correct the problem. Then go to step 4 .

Analog Circuitry Voltages
4. When the ION-1 front paral is operational, check the \pm 15 -Vdc supply voltages at the analog integrated circuits (see Dwg No. 101Y-230858-D1). With the power switch ON, measure the $+V^{\prime}$ and $-y^{\prime}$ yoltage levels at chips U2, U7, and U8 (see Table II). The absolute value of the test points should be $\geq 5.4 \mathrm{~V}$.

IF the value is $\geq 5.6 \mathrm{~V}$, yo to step 5 .

IF the value is $<5.6 \mathrm{~V}$, do the following. Turn the power switch UFF. Remove chips U2, U7, and U8.

CAUTION: Handle chips U2, U7, and U8 with MOS and CMOS handling procedures.

Turn the power switch ON and remeasure the test points. If the absolute values are still $<5.6 \mathrm{~V}$, turn the power switch OFF and do the following: 


\section{TABLE II}

$\pm V$ ' VOLTAGE CHECK POINTS

(DWG NO. 101Y-230858-D1)

\begin{tabular}{lcc} 
& \multicolumn{2}{c}{ Pin Number } \\
\cline { 2 - 3 } Chip & $+V^{\prime}$ & $-V^{\prime}$ \\
U2 & 7 & 4 \\
U7 & 11 & 8 \\
U8 & 11 & 8
\end{tabular}

Analog Circuitry Voltages (cont)
Replace CR4 for a bad $+V^{\prime}$ and/or CK5 for a bad $-V^{\prime}$.

Replace chips U2, U7, and U8 one at a time (turn the power OFF during replacement) to find which one pulls the absolute value below $5.6 \mathrm{~V}$. Replace that crip with a new one.

If the absolute value of the test points is stil1<5.6 V, check and replace R15, R16, $\mathrm{C} 15$, and/or C24.

5. Turn the power $\mathrm{ON}$. Monitor the voltage at pin 23 of 416 (Dwg. No. 101Y-230858-D1) with a digital voltmeter. Adjust R43 to make this voltage $-10.00 \mathrm{Vdc}$.

6. Adjust R39 to obtain a voltage of $-5.00 \mathrm{Vdc}$ at pin 15 of U15. Make sure that jumper 12 is in place by connecting pins 2 and 3 of UI5. 
PULSE CHANMEL ADJUSTMENTS
7. Referring to Dwg No. 101Y-230858-D1, make sure that a 5000-2, $1 \%$ resistor is installed for $\mathrm{R} 5,220 \mathrm{pF}$ for $\mathrm{C8}$, and $10 \mathrm{pF}$ for $\mathrm{C9}$. Connect an oscilloscope to the AMP OUT LEMO connector on the rear pane1.

Adjust R38 for an output of $0.00 \pm 0.01 \mathrm{Vdc}$.

Use a pulse generator to supply positive pulses

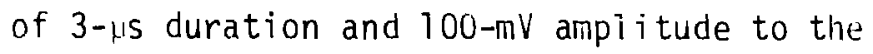
FISSION CHAMBER INPUT BNC connector on the rear pane1.

Verify that differentiated pulses are present at IMP OUT. The amplitude of the output pulses depends upon the input pulse risetime and amplitude.

Using the controls of the pulser, adjust the input pulse amplitude as necessary to produce a positive output pulse height of 3 to $4 \mathrm{~V}$.

\section{LLD Function}

8. Using the keypad, select the low-level discriminator (LLD) function.

Connect an oscilloscope probe to pin 2 of $U 1$. Change the LLD threshold level (using the keypad) and verify that the voltage on pin 2 changes in accordance with Table III.

The ac ripple voltage should be $20 \mathrm{mV}$ peak-topeak or less. The number in parentheses on the 
TABLE II I

LLD SETPOINT VOLTAGES

\begin{tabular}{|c|c|c|}
\hline $\begin{array}{l}\text { LLD } \\
\text { Setpoint }\end{array}$ & $\begin{array}{l}\text { Pin } \\
\text { Ui } \\
\text { (V) }\end{array}$ & $\begin{array}{c}\text { LLD } \\
\text { Readout } \\
\end{array}$ \\
\hline $\begin{array}{r}10 \\
50 \\
100 \\
250\end{array}$ & $\begin{array}{l}0.19 \\
0.99 \\
1.96 \\
4.89\end{array}$ & $\begin{array}{r}10 \\
50 \\
100 \\
249\end{array}$ \\
\hline
\end{tabular}

LLD Function (cont) liquid crystal display (LCD) is tha voltage being read by the internal analog-to-digiti: converter $(A D C)$. The units are relative, ranging from $0(\sim 0 V)$ to $255(\sim 5 \mathrm{y})$. The LCD readout should equal the LLD threshold setpoint \pm 2 counts.

Return the LLD to its original value $(30)$. Trigger pulses should be present at pin 1 of U3.

Connect the oscilloscope probe to U3, pin 13.

Neutron Channel Logic Pulse
Adjust the values of $R 7$ and $C 7$ as necessary to produce a positive pulse at pin 13 with a duration of 10- to 13-us. Ensure that the displayed value of counts/s agrees with the repetition rate of the input pulses.

Increase the LLD threshold voltage until zero counts/s are registered. The LLU reading where this occurs should be $\left(v_{p} \times 225 / 5\right)$, where 
Neutron Channe?

Logic Pulse

(cont)

CURRENT CHANNEL ZERO ADJUSTMENT
$V_{p}$ is the pulse height measured at the amplifier out. Reduce the threshold to 30 and disconnect the pulse generator.

9. Refer to Owg No. 101Y-230858-01. Ensure that pin 3 of $U 2$ is connected to ground; R10 equals $0 \Omega$. With the copper-clad shield board in place above the analog input section of the main electronics board, select the GAIN function on the front panel and enter a 1 for the manual mode.

Sei tha gàin to 1 E3840 and connect an 0scilloscope probe to pin 13 of U10. Adjust R9 (Fig. 3) for a dc baseline of approximately $-1.00 \mathrm{~V}$ as read from the scope. This should produce an ADC count of approximately 1600.

Step through all eight gain settings to ensure that the offset voltage does not exceed $0 \mathrm{~V}$. The offset varies with changes in gain, but over a short term it should remain constant for a given gain setting.

Crystal Frequency

10. Use an oscilloscope probe to connect the input of a frequency counter to pin 9 of U20 (DWg No. 10 Y Y-230858-D2). Adjust C62 for an output frequency of $2.457 \pm 0.0005 \mathrm{MHz}$. 
BIAS SUPPLY YOLTAGE ADJUSTMENTS

Ion Chamber

Bias Range

Fission Chamber

Bias Voltage Range

Preamp Power Voltages

Yoltage Readout

Current Channel
11. Referring to Dwg No. 101Y-230839-04, locate potentiometers R33 and R44 or the power supply board (Fig. 4).

Connect a high-input impedance $110 \mathrm{M}$ minimum) voltmeter to the socket of the ION CHAMBEP INPUT twin-axial connector on the rear panel. The bias voltage should vary between 0 ind $-425 \mathrm{Vdc}$ as you turn $\mathrm{R} 43$ through its adiustment range. The standard setpoint for the ion chamber bias is $-100 \mathrm{Vdc}$.

Using a high-voltage probe or a voltmeier capable of measuring tu $2000 \mathrm{Vdc}$, monitor the ilas voltage at the FISSION CHAMBER H.V. SHV connector. As you adjust R44, the output should change from +500 to $+1500 \mathrm{Vdc}$. The standard setpoint for the fission chamber bias is $+750 \mathrm{Vdc}$.

Check the PREAMP POWER connector for ground on pin $1,+15 \mathrm{Vdc}$ on pin 4 , ind $-15 \mathrm{Vdc}$ on pin 9.

12. Step through the values shown on the front panel VOLT display to ensure that they agree nominally with the measured values.

13. Use an adapter cable to connect a picoampere source, such as a Keithly Model 261, to the pin of the ION CHAMBER INPUT twin-axial connector. Although the ION-1 acquires only a relative current reading from an ion chamber, the absolute current calibration is 
Current Channe1

(cont)

in close agreement between the units. Tables

IV through VIII show the measured values for ma in circuit board No. 10. Use these values as a guide for checking the operation and calibration of the unit being tested. Investigate any large variations from the tables. Minus signs have been onitted for clarity; remer.ser that all values shown are negative.

TABLE IV

ADC ZERO VÁLUES

\begin{tabular}{rrrr} 
Gain & & ADC \\
\cline { 1 - 1 } 163840 & & 1836 \\
40960 & & 1996 \\
10240 & & 2036 \\
2560 & & 2046 \\
640 & & 1836 \\
160 & & 1997 \\
40 & & 2037 \\
10 & & 2047
\end{tabular}

TABLE $V$

ANALOG CHANNEL CALIBRATION VALUES

Input Current

\section{(A)}

$3.5 \times 10^{-11}$

$3.5 \times 10^{-10}$

$3.5 \times 10^{-9}$

$3.5 \times 10^{-8}$

$3.5 \times 10^{-7}$

\begin{tabular}{c} 
GG \\
\hline 0.1293 \\
1.294 \\
12.75 \\
128.4 \\
1288.
\end{tabular}

1288.
Gain $A D C$ Net $A D C$

$\begin{array}{lll}163840 & 2679 & 843\end{array}$

$10240 \quad 2566 \quad 530$

$\begin{array}{lll}640 & 2163 & 327\end{array}$

$\begin{array}{lll}160 & 2821 \quad 824\end{array}$

$\begin{array}{lll}10 & 2562 & 515\end{array}$ 


\section{TABLE VI}

TYPICAL ANÄLOG CHANNEL VALIJES

\begin{tabular}{|c|c|c|c|c|}
\hline $\begin{array}{c}\text { Input Current } \\
\text { (A) }\end{array}$ & $\mathrm{GG}$ & Gain & $\underline{A D C}$ & Net $A D C$ \\
\hline $5.00 \times 10^{-12}$ & 0.0190 & 163840 & 1958 & 122 \\
\hline $2.00 \times 10^{-11}$ & 0.0739 & 40960 & 2117 & 121 \\
\hline $8.00 \times 10^{-11}$ & 0.2965 & 10240 & 2158 & 122 \\
\hline $3.20 \times 10^{-10}$ & 1.174 & 2560 & 2167 & 121 \\
\hline $1.28 \times 10^{-9}$ & 4.575 & 640 & 1955 & 119 \\
\hline $5.12 \times 10^{-9}$ & 18.57 & 160 & 2117 & 120 \\
\hline $2.05 \times 10^{-8}$ & 75.00 & 40 & 2158 & 121 \\
\hline $8.19 \times 10^{-8}$ & 300.0 & 10 & 2167 & 120 \\
\hline $1.00 \times 10^{-11}$ & 0.0369 & 163840 & 2076 & 240 \\
\hline $4.00 \times 10^{-11}$ & 0.1479 & 40960 & 2239 & 24.3 \\
\hline $1.60 \times 10^{-10}$ & 0.5905 & 10240 & $2 ? 79$ & 243 \\
\hline $6.40 \times 10^{-10}$ & 2.367 & 2560 & 2289 & 243 \\
\hline $2.56 \times 10^{-9}$ & 9.267 & 64.0 & 2075 & 239 \\
\hline $1.02 \times 10^{-8}$ & 37.29 & 160 & 2237 & 240 \\
\hline $4.10 \times 10^{-8}$ & 151.3 & 40 & 2279 & 242 \\
\hline $1.64 \times 10^{-7}$ & 597.5 & 10 & 2286 & 239 \\
\hline $2.00 \times 10^{-11}$ & 0.0736 & 163840 & 2315 & 479 \\
\hline $8.00 \times 10^{-11}$ & 0.2963 & 40960 & 2482 & 486 \\
\hline $3.20 \times 10^{-10}$ & 1.183 & 10240 & 2521 & 485 \\
\hline $1.28 \times 10^{-9}$ & 4.734 & 2560 & 2531 & 485 \\
\hline $5.12 \times 10^{-9}$ & 18.65 & 640 & 2315 & 479 \\
\hline $2.05 \times 10^{-8}$ & 75.19 & 160 & 2480 & 483 \\
\hline $8.19 \times 10^{-8}$ & 301.9 & 40 & 2520 & 483 \\
\hline $3.28 \times 10^{-7}$ & 1208. & 10 & 2530 & 483 \\
\hline
\end{tabular}


TABLE VII

TYPICAL ANALOG CHANNEL VALUES

\begin{tabular}{|c|c|c|c|c|}
\hline $\begin{array}{l}\text { Input Current } \\
\text { (A) }\end{array}$ & GG & Gain & $A D C$ & Net ADC \\
\hline $4.00 \times 10^{-11}$ & 0.1477 & 163840 & 2800 & 964 \\
\hline $1.60 \times 10^{-10}$ & 0.5902 & 40960 & 2962 & 966 \\
\hline $6.40 \times 10^{-10}$ & 2.369 & 10240 & 3004 & 968 \\
\hline $2.56 \times 10^{-9}$ & 9.467 & 2560 & 3015 & 969 \\
\hline $1.02 \times 10^{-8}$ & 37.30 & 640 & 2791 & 955 \\
\hline $4.10 \times 10^{-8}$ & 150.7 & 160 & 2963 & 966 \\
\hline $1.64 \times 10^{-7}$ & 604.4 & 40 & 3004 & 967 \\
\hline $6.55 \times 10^{-7}$ & 2410. & 10 & 3012 & 965 \\
\hline
\end{tabular}

TABLE VIII

ANALOG CHANNEL CALIBRATION CONSTANTS

\begin{tabular}{rc} 
Gain & $\begin{array}{c}\text { Measured } \\
\text { Current/Volta } \\
(\mathrm{A} / \mathrm{V})\end{array}$ \\
\cline { 2 - 2 } 10 & $1.38 \times 10^{-7}$ \\
40 & $3.45 \times 10^{-8}$ \\
160 & $8.64 \times 10^{-9}$ \\
640 & $2.17 \times 10^{-9}$ \\
2560 & $5.39 \times 10^{-10}$ \\
10240 & $1.35 \times 10^{-10}$ \\
40960 & $3.36 \times 10^{-11}$ \\
163840 & $8.28 \times 10^{-12}$
\end{tabular}

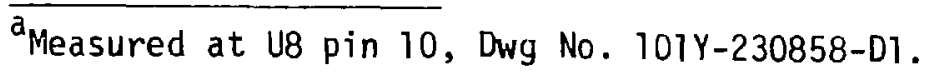


See Dwg No. 101Y-230858-D1. The current channel (the circuitry that processes the current from the ion chamber) converts the current into a voltage and then digitizes the voltage for display.

Because of the extreme sensitivity of the current channel, the input (connector J2) to the current channel is connected to the input (pin 2) of amplifier U2 with Teflon-insulated wire and the junction is a standoff with a Teflon base.

Amplifier U2 is a current-to-voltage converter. Relay $K 1$ selects between the two U2 conversion gains. Table IX lists the conversion gains and time constants.

\section{TABLE IX}

CONVERSION GAINS AND TIME CONSTANTS

\begin{tabular}{lcc}
$\begin{array}{c}\text { Relay } \\
\text { K1 }\end{array}$ & $\begin{array}{c}\text { Conversion } \\
\text { Gain } \\
(\mu \mathrm{V} / \mathrm{pA})\end{array}$ & $\begin{array}{c}\text { Time } \\
\text { Constant }\end{array}$ \\
\cline { 2 - 3 } $\begin{array}{c}\text { Open } \\
\text { Closed }\end{array}$ & 100 & $0.2 \mathrm{~s}$ \\
0.75 & $7.5 \mathrm{~ms}$
\end{tabular}

Resistor R9 adjusts for current and voltage zero offsets. The U2 output is filtered by R12, C23, with a time constant of $0.22 \mathrm{~ms}$. Amplifier $U 7$ is a fixed-gain (10.24), auto-zero amplifier.

U9 and 48 form a variable-gain auto-zero stage, with gain values of $1,4,16$, and 64 . The output of this stage feeds a $47-m s$, time-constant filter 
CURRENT CHANMEL

(cont)
R48, C46, and the input to channel 0 of the arialog multiplexer (MUX), U10. Table X lists all inputs to the MUX.

TABLE $X$

ANALOG MULTIPLEXER INPUT SIGNALS

\section{Channe1}

0

1

2

3

4

5

6

\begin{tabular}{l} 
Signal \\
\hline Current input \\
Fission chamber bias \\
Ionization chamber bias \\
$5-V$ supply \\
Battery voltage \\
LLD voltage \\
$-15-V$ supply \\
$+15-V$ supply
\end{tabular}

ADC Multiplier

a

1.000489

0.2501221

0.0100489

0.0200098

0.0050024

0.0185276

0.0185276

aConstants for each gain are listed in the User Manual in GAIN COMMAND.

ANALOG MULTIPLEXER

AND ANALOG-TO-DIGITAL CONVERTER.
The channels are digitally selected through software. The analog multiplexer (MUX) output feeds a 12-bit analog-to-digital converter (ADC), U16, which has an internal $-10 \mathrm{~V}$ reference that can be adjusted with potentiometer R43 (see Ion Chamber Bias Range under TESTING AND ADJUSTMENT).

The conversion clock for the $A D C$ is derived from the microprocessor system clock. The start synchronization is done with U17, U18, and associated circuitry. The microprocessor issues the start command and then waits for the end-of-convert (EOC) signal from the ADC. 


\section{ANALOG MULTIPLEXER \\ AND ANALOG-TO-DIGITAL \\ CONYERTER \\ (cont)}

The displayed value of the channel being measured depends on the gain of the channel. The gain is a function of the state of $K I$ and the gain selected by the U9, U8 stage. The LLD value is a direct input, but the remaining inputs have voltage divider networks. The microprocessor mul tiplies the net $A D C$ reading by the appropriate conversion factor from Table $X$ and arrives at the displayed value. Hence, any design modification requires a software modification.

A unique feature of ION-1 is its ability to correct for day-to-day changes in the offset and leakage currents in the current channel. These changes can arise from changes in humidity, for example.

The dynamic range of the $A D C$ is $\pm 10 \mathrm{~V}$. The dynamic range used by the current channel is $\sim 5 \mathrm{~V}$. The zero of the current channel is adjusted significantly $(n-1 \mathrm{~V})$ below 0 .

When you first turn on the unit, the microprocessor prompts you to disconnect the ion chamber input cable. It then reads the offset or zero values for all eight gain settings. When ION-1 makes actual measurements, it subtracts offset for the gain being used from the $A D C$ reading and obtains the net $A D C$ value.

PULSE CHANNEL 
PULSE CHANHEL

(cont) (connector $\mathrm{J1}$ ), and $\mathrm{U4}$, which has a $1-\mu \mathrm{s}$ integration constant, amplifies the differentiated signal.

The output of the amplifier feeds comparator $U 1$. The DAC, U15, sets the LLD value. The reference voltage for $U 15$ is derived from the internal reference of $U 16$ and is adjusted with R39.

Comparator-output pulses trigger a one-shot, U3, which interrupts the microprocessor. The pulse width of the one-shot is adjusted between 10 and $15 \mu \mathrm{s}$. (NOTE: Counting dead-time is determined by the software interrupt-servicing routine.)

The counter is a software register, not a hardware register.

\section{POWER SUPPLY}

Battery Supply
See Dwg No. 101Y-230839-D4. The need to minimize battery drain complicates the generation of the various voltages required by ION-1. Switching power supplies were used to obtain high efficiency.

The battery supply consists of two parallel banks of six NiCad D-cells in series. ION-1 can operate on a single bank. The charging circuit charges both banks in series to make the ION-1 unit operable with the MCA charger. Relay KI operates off the charger input and switches the battery banks from parallel to series. When you plug in the 
Battery Supply

(cont)

Digital and Analog Voltages charger, $12 \mathrm{~V}$ is applied to the power supply board circuitry through the LM-340T-12 regulator.

Three basic supply voltages $(+5$ and \pm 15$)$ and two bias supply voltages are generated (ion chamber bias is adjustable from 0 to $-425 \mathrm{~V}$, and fission chamber bias is adjustable from +500 to $+1500 \mathrm{~V}$ ).

The $+5-V$ supply is composed of chips $Z 2, Z 3$, and 27. Chip $Z 2$ generates $-18 \mathrm{~V}$, and $\mathrm{Z7}$ generates +18 V. R10 and R27 determine the voltage setpoints of these chips. Capacitors $\mathrm{ClO}$ and $\mathrm{Cll}$ filter the outputs. Chip 23 is a dual-balanced tracking regulator. The output of this regulator is $\pm 15 \mathrm{~V}$, and the outputs are filtered with $\mathrm{C} 16, \mathrm{C} 17$, and $\mathrm{C} 19$.

Bias Voltages

Voltage Display
Commercial dc-dc converters (Venus Q-15) generate the bias voltages. The supply voltages are controlled by R33 for the ion chamber bias and R44 for the fission chamber bias. The Q-15's and the associated filters and dividers are mounted on the internal rear panel inside a metal cover, providing both shielding and protection.

ION-1 can display the digital, analog, bias, and battery supply voltages. Resistors R18 and R19 form the voltage divider that supplies the $+5-V$ input to the $A D C$ on the main electronics board. R2O and R21 form a similar divider for the $+15-V$ supply. The $A D C$ expects a positive unipolar input; hence, the $-15-V$ supply signal is inverted by 24 , which has less-than-unity gain. 
Voltage Display

(cont)
Chip $Z 6$ is an inverter-buffer for the ion chamber bias readout. Chip $Z 5$ is the buffer for the fission chamber bias divider that feeds the ADC.

On the main circuitry board (Dwg No. $101 Y-230839-01), \pm 5.6 \mathrm{~V}$ is required for the ICL 7600 amplifiers. Zener regulators CR4, CR5, R15, and R16 generate the voltages. The regulators use the $\pm 15-V$ supplies for their source.

DIG'TAL CONTROL PROCESSOR The heart of ION-1 is a Motorola M6802 microprocessor used for control, data acquisition, diagnostics, and calculations. Dwg No. 101Y-230858-D2 shows the main digital circuitry. The firmware is software stored in read-only memory (ROM), in chips U41-U47. The random-access memory (RAM) is in chips U38-U39.

Front Pane1

The main communication with the microprocessor is through the front-panel keyboard and display. The interface is executed through chips U29-U31. The front-panel circuitry (Dwg No. 101Y-230839-D3) consists basically of a keypad encoder $\mathrm{Zl}$, a display memory $Z 3(32 \times 8)$ holding the display characters, and a character generator ROM Z6. Connector P2 connects the LCD module (EPSON MA-B956B) to the board.

LCD Module

The LCD module provides character addresses, P2 pins 12-16, and row scan addresses, P2 pins 9-11. Chips 210 and 211 apply the character row data to the LCD module. These exclusive OR gates allow 


\section{LCD Module}

(cont)

\section{Keypad Scan}

Serial Interface inverse character display when bit 7 of the character data is set $(>2 \mathrm{~V})$. Chips 25 and $Z 4$ are three-state buffers that feed the appropriate address information to the display memory 23 . Chips 28 and 212 furnish the appropriate gating of $Z 4$ and 25 , as well as the write-data strobe for 23 .

Chip 21 scans the keypad. When a key is pushed, the data-available line 21 , pin 13, goes high and stays high as long as the key is pressed. This level is fed to the microprocessor through data 1 ine DO on chip U29 of the main electronics board (Dwg No. 101Y-230858-D2). The going high of the data-available line sets the $Q$ output of 27 (Dwg No. 101Y-230839-D3), which indicates that there has been a key push since the last read of the $\mathrm{Zl}$ output. The $Z 7$ output is reset by the signal from 212 , pin 12, which is strobed by the trailing edge of the read-enable pulse that transfers the 21 data tr the microprocessor through chip U29 on the main electronics board.

Additional communication with the processor is made with an RS-232 leve1 compatible serial interface. Chip U22 (Dwg No. 101Y-230839-D3) is the seriai interface chip used. The baud rate is set from software using circuitry associated with chip U20. The level shifting for the input/output is done using the circuitry between connector P2 and the serial interface.

\section{Real-Time Clock}

Chip U25 and the MM5368 generate the real-time clock interrupts. Interrupts occur every $200 \mathrm{~ms}$. 


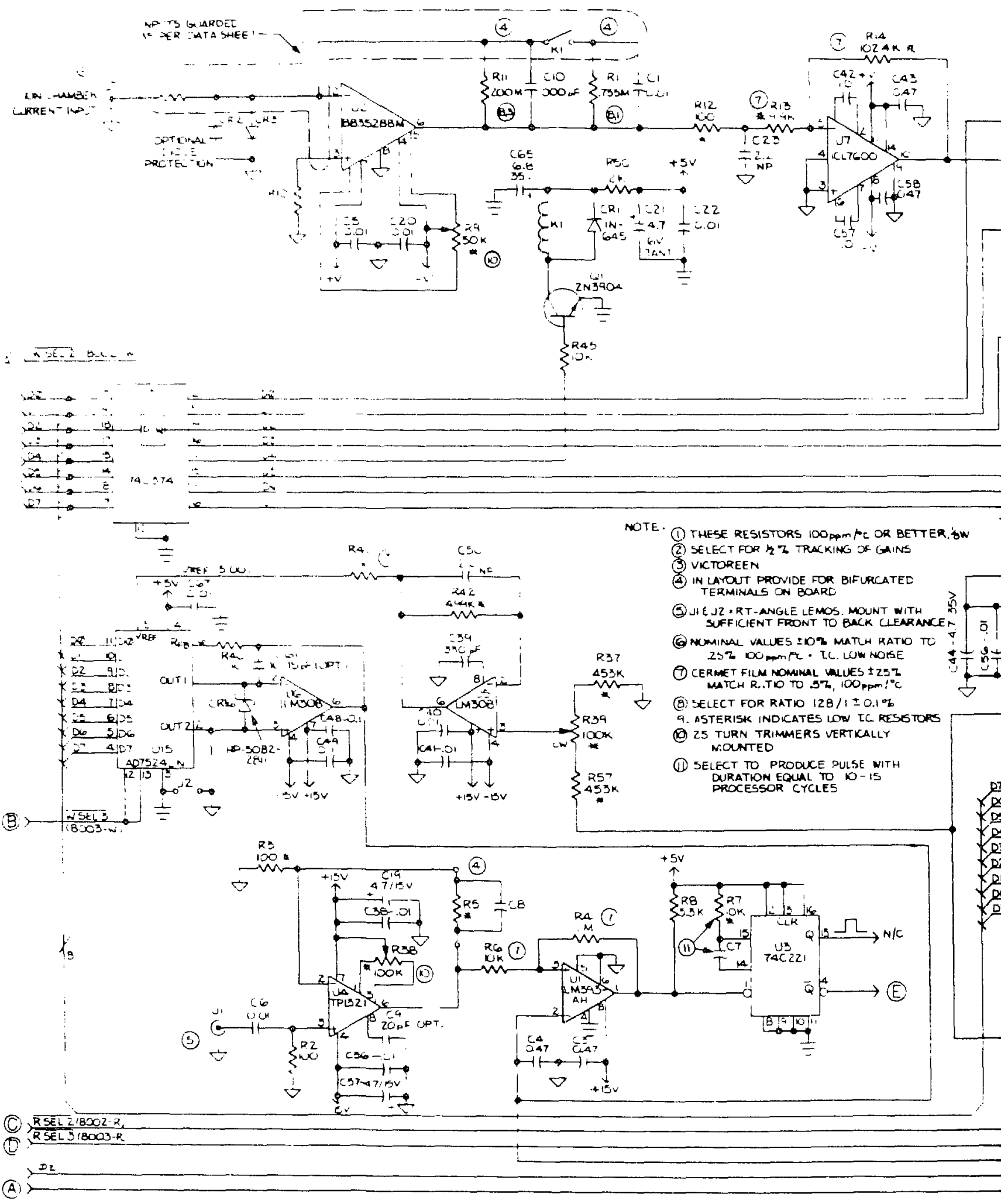


(1)
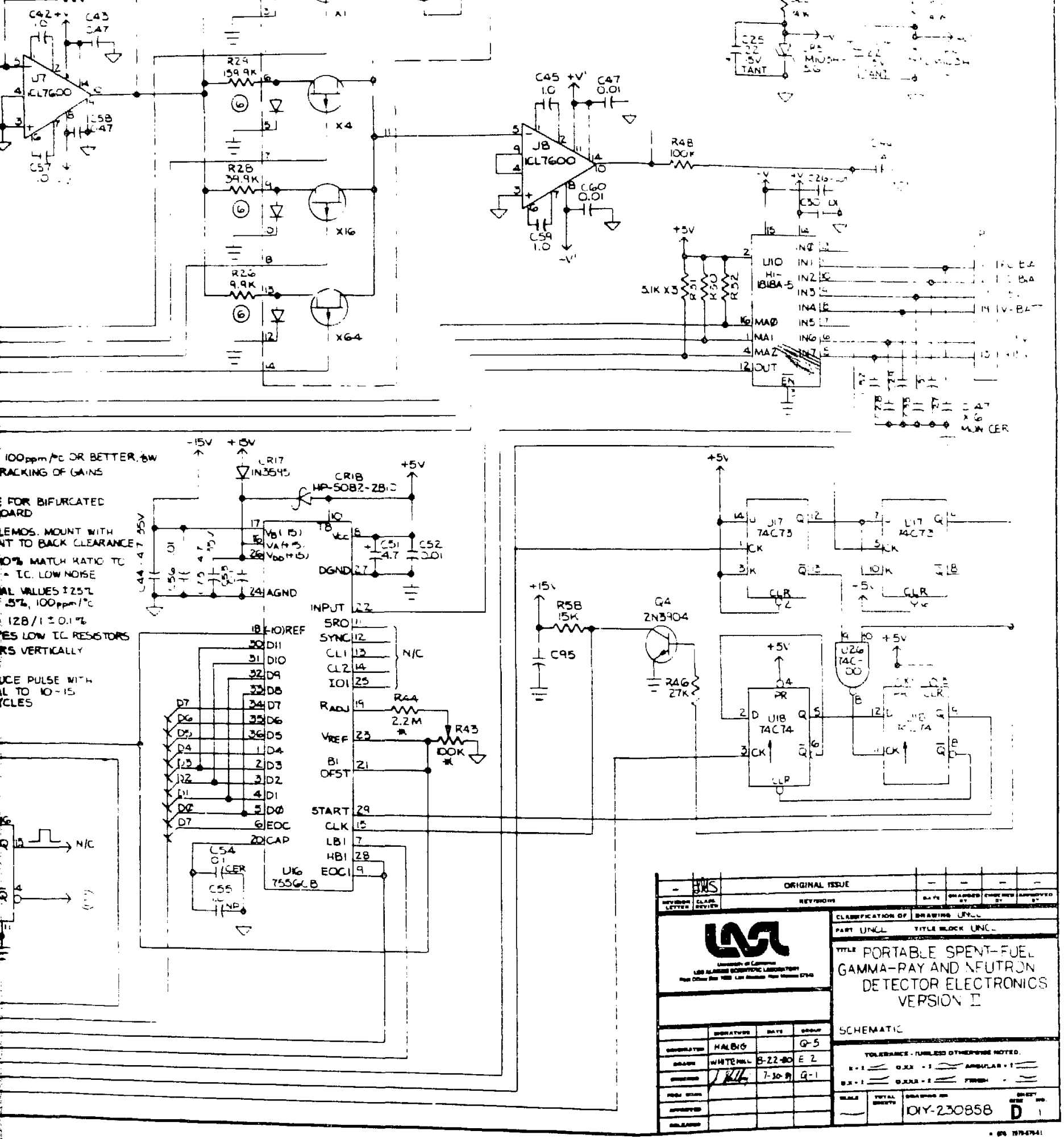
F.: intions

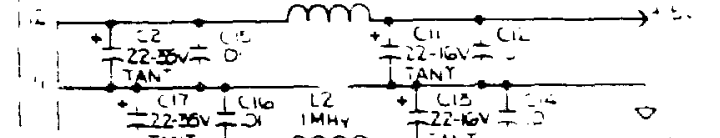

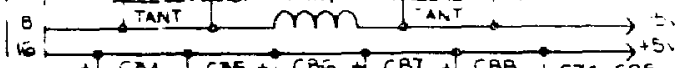

$+10341 C 35+\frac{C 80}{+1 C B 7+1 C 88+1 C 74-C 85}$

$1 \longrightarrow$ TAMT $\longrightarrow$ TANT, TANT TANT, D

$10 \div \frac{1010+000}{10}=$

$20 \longrightarrow$

$\sqrt[15]{\square}$

rrom. 23000 B. DI

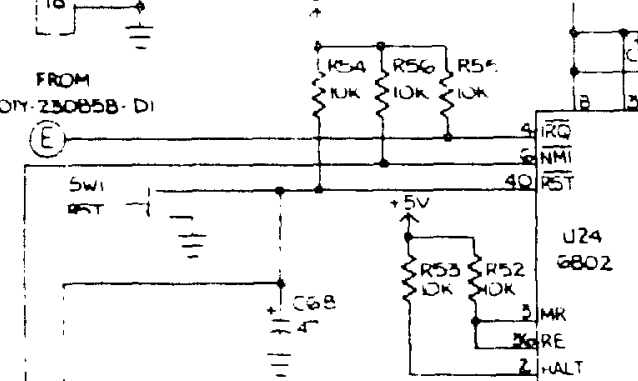

i

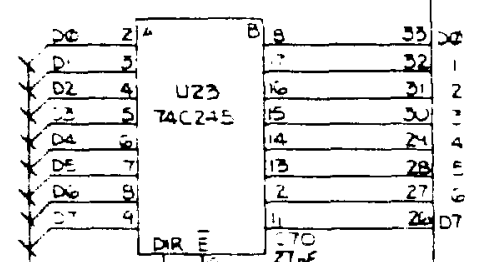

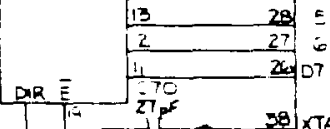

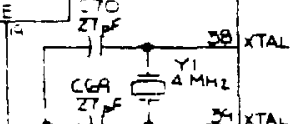

$\div$

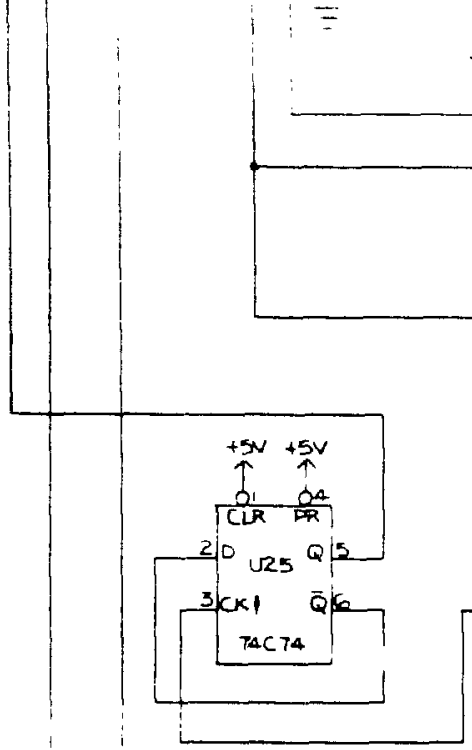

PUTE:

1. ON ALL TAC24A'S, PINS! E MARE GNE

2. ALL RESISTORS = $1 / 4 \mathrm{~W}$

(3) DROVIDE JULDER MTLETS ON DESIGNATED UNUSED DH:

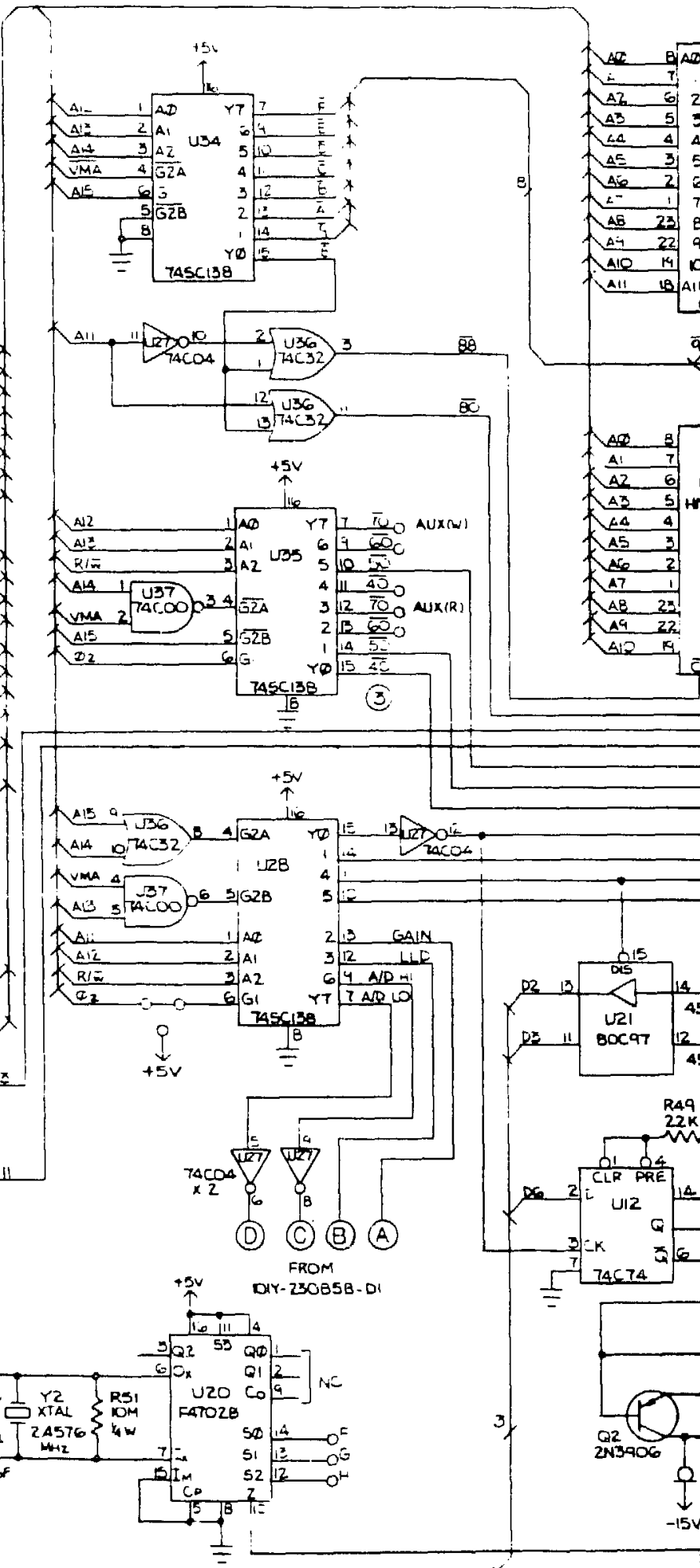




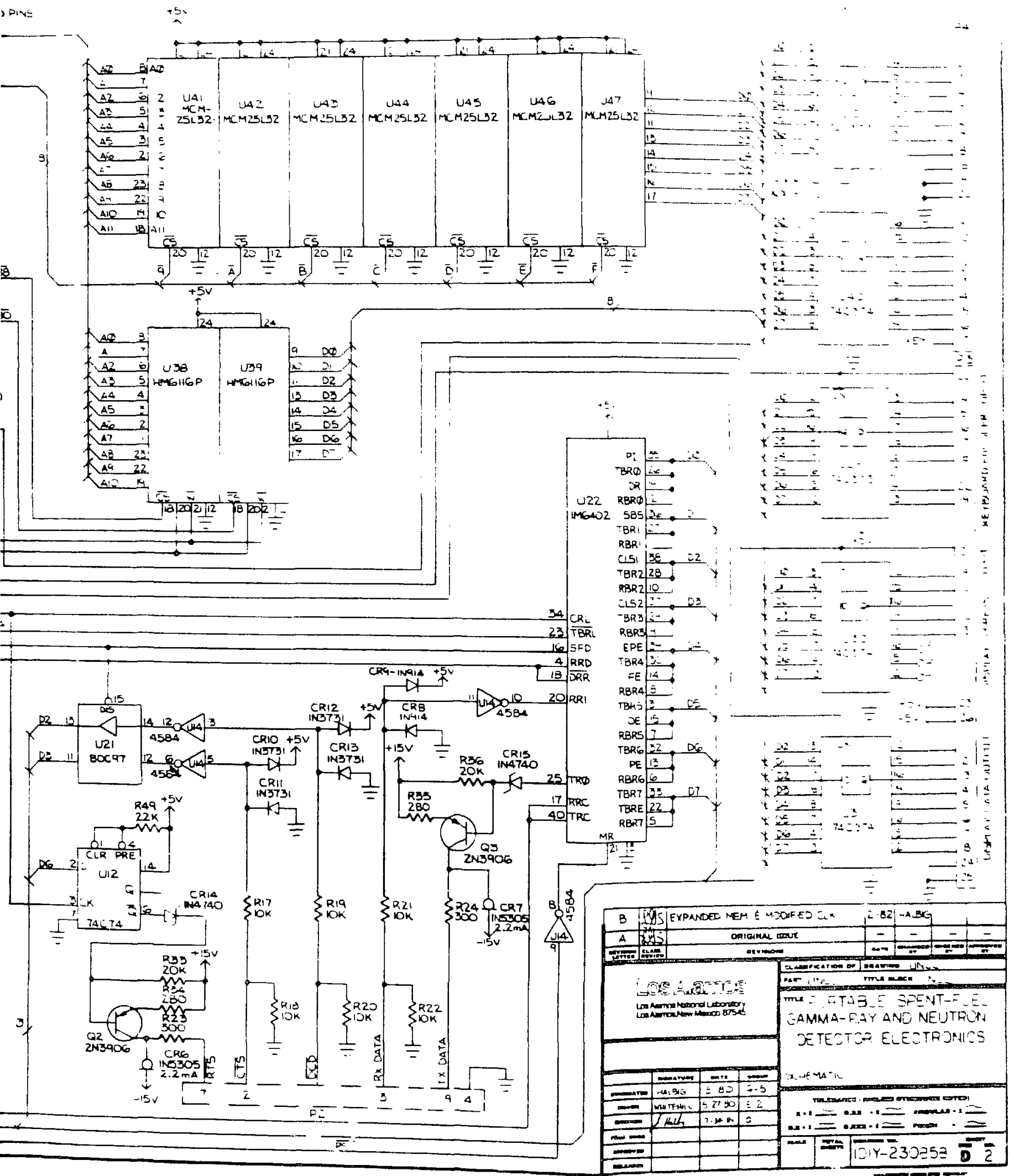




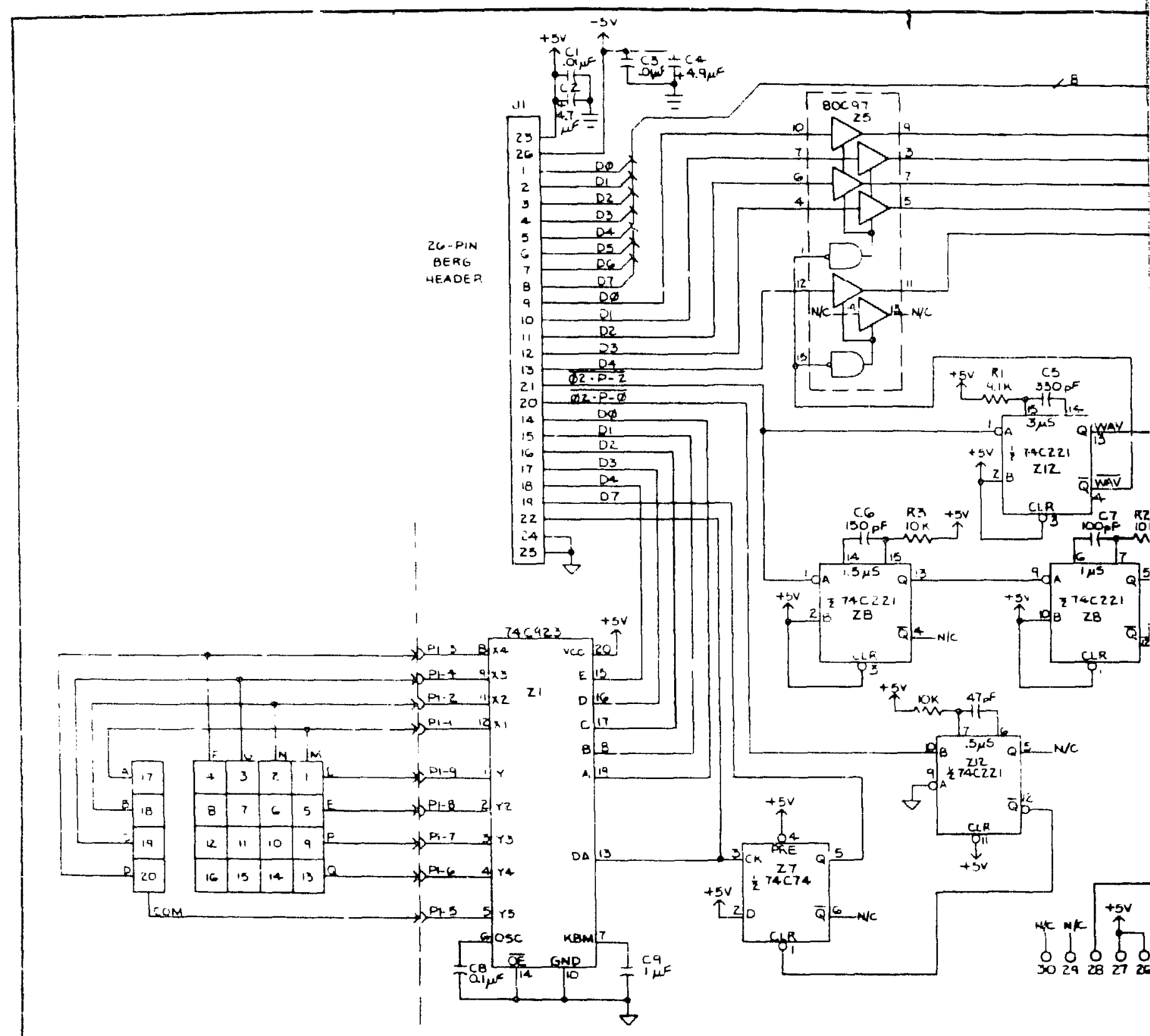




\section{$=-2=$}

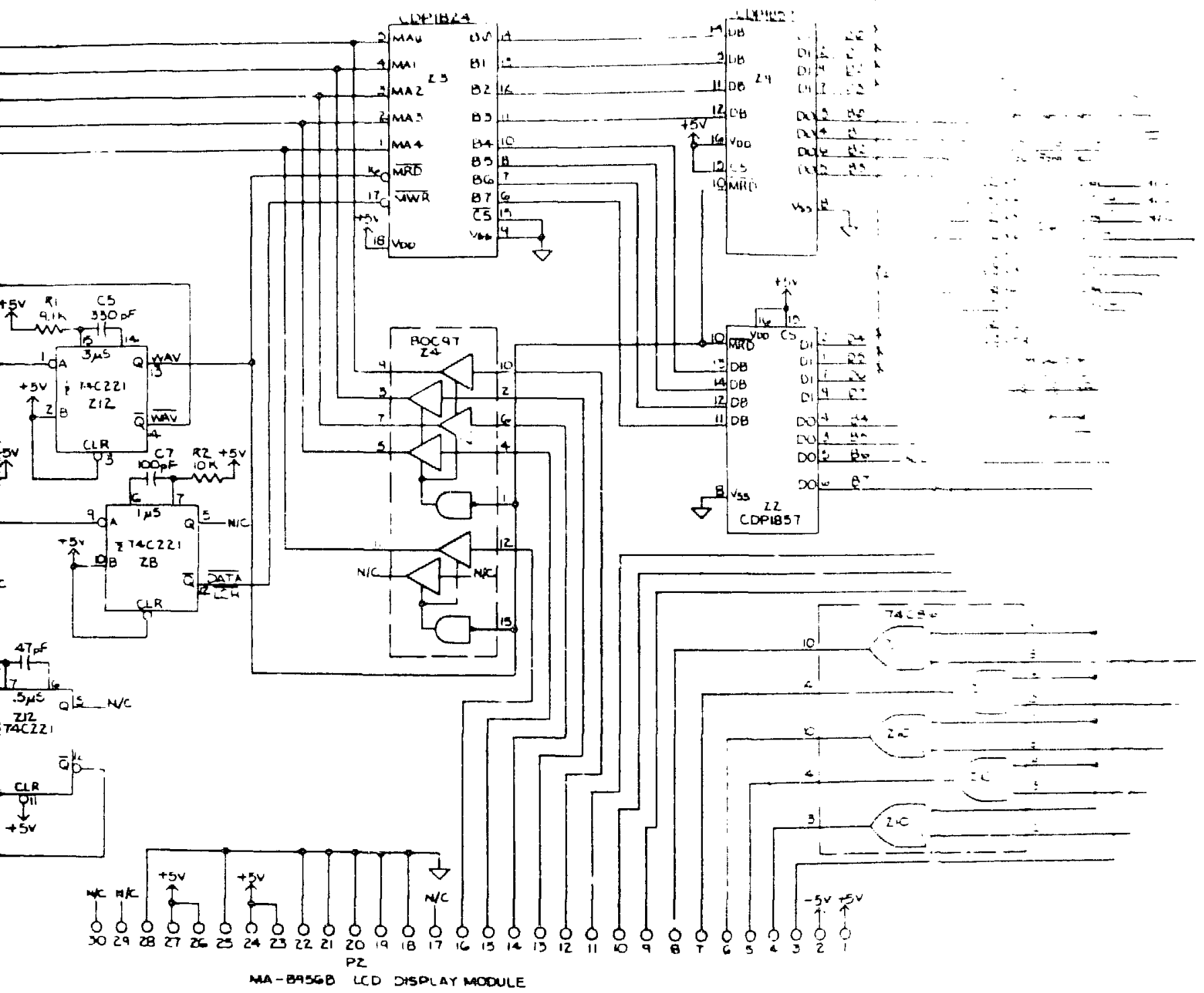

MA-BA5GB LCD PHSLLAY MOOULE

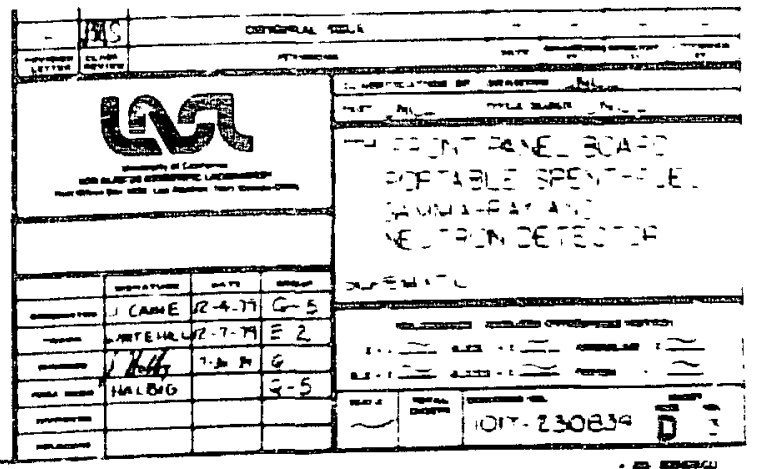




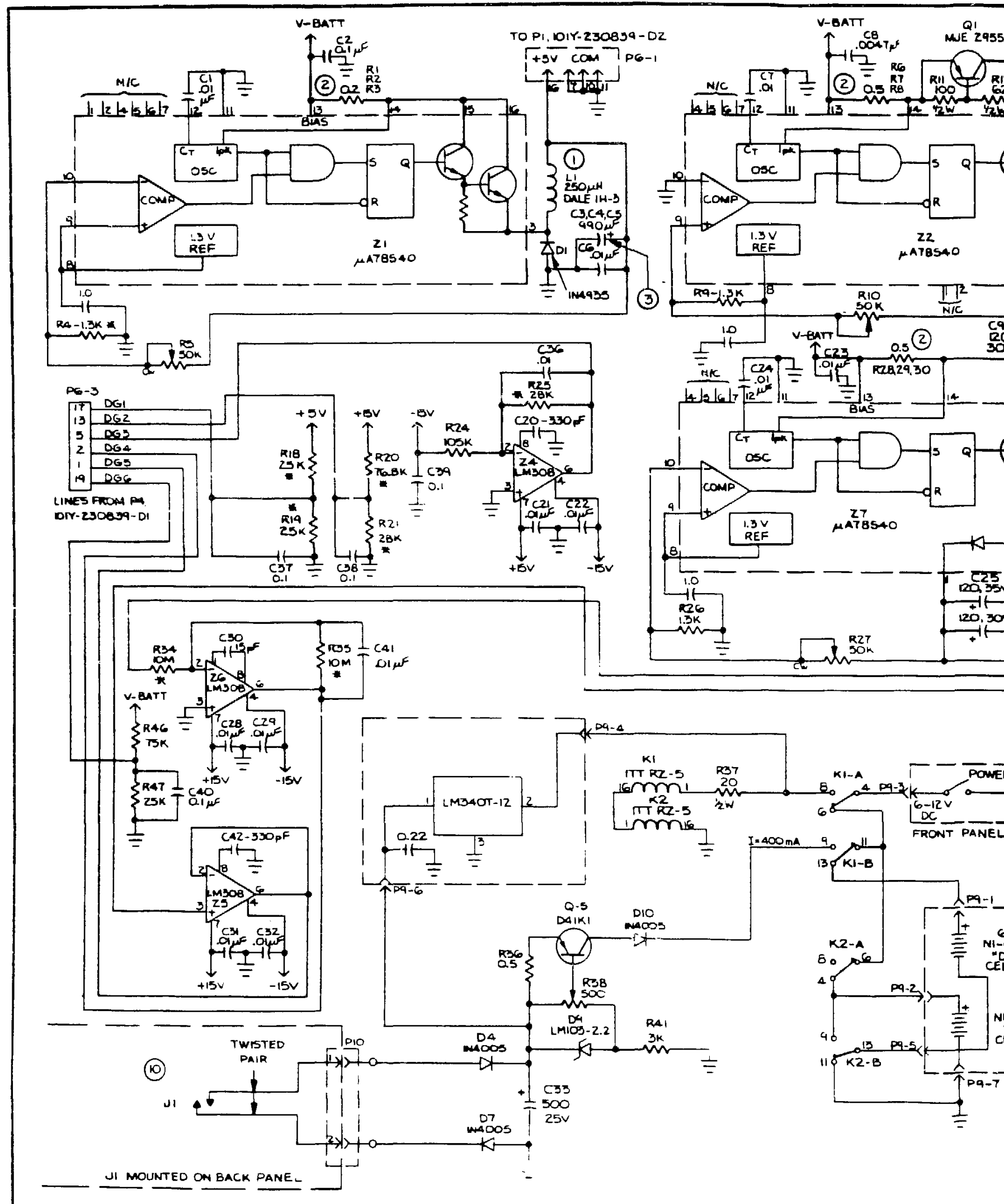




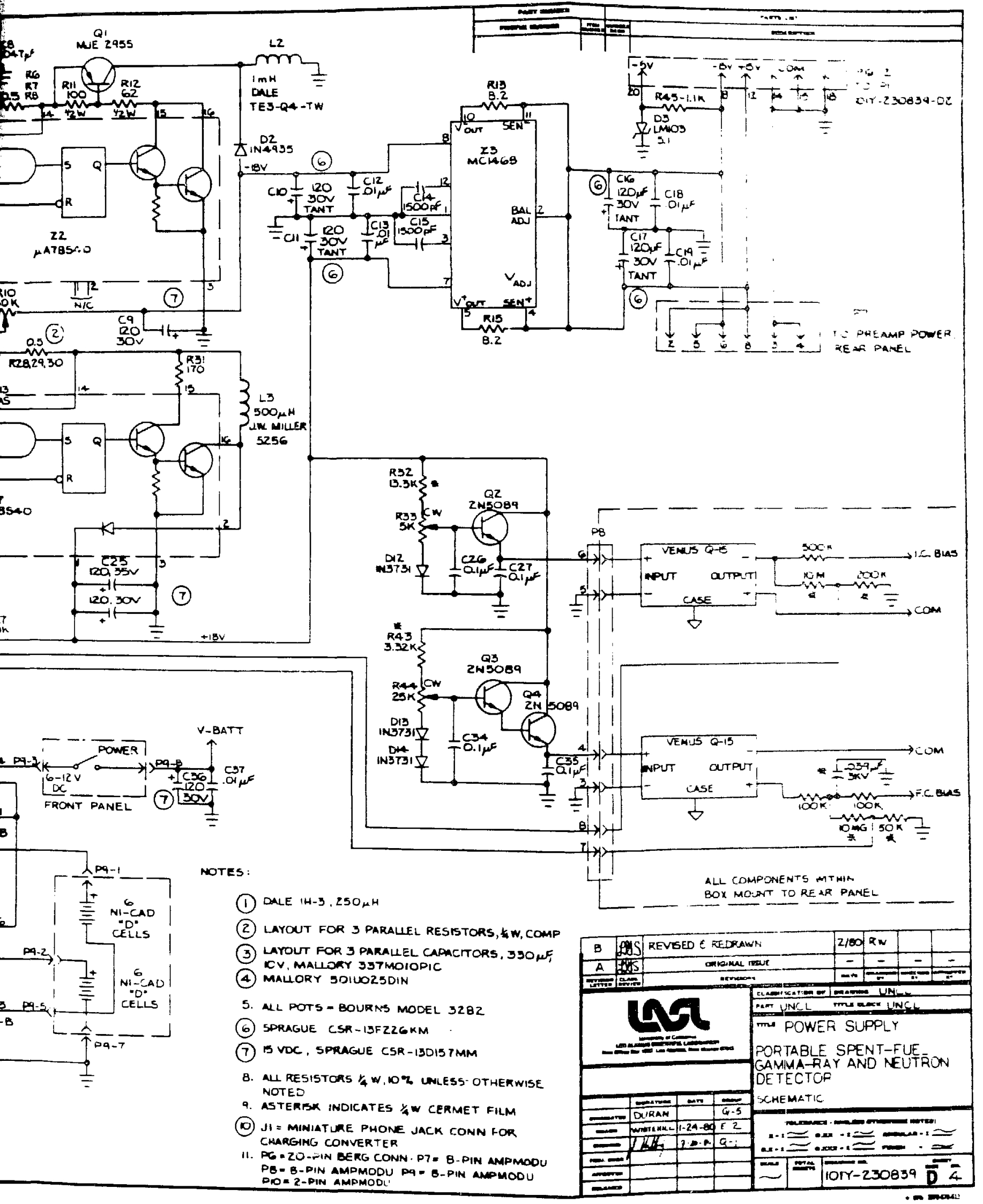

